\title{
The Adoption of the Green Marketing in the Millennium Generation
}

\author{
Flor Madrigal Moreno ${ }^{1}$, Fernando Ávila Carreón ${ }^{1} \&$ Salvador Madrigal Moreno ${ }^{1}$ \\ ${ }^{1}$ School of Accounting and Administrative Sciences, Universidad Michoacana de San Nicolás de Hidalgo, \\ Morelia, Michoacán, México \\ Correspondence: Salvador Madrigal Moreno, School of Accounting and Administrative Sciences, Universidad \\ Michoacana de San Nicolás de Hidalgo, Michoacán, México. E-mail: smadrigal@umich.mx
}

Received: January 12, 2016 Accepted: February 2, 2016 Online Published: March 25, 2016

doi:10.5539/ijms.v8n2p97 URL: http://dx.doi.org/10.5539/ijms.v8n2p97

\begin{abstract}
This descriptive study shows the evolution in the behavior of the millennium consumer, the influence of the culture, the society and the globalization in the making decisions. The millennium generation is well recognized as the generation whose consumptions are more oriented to ecological products. Also, their concern about the ecological impact of the supplies they use in their daily life, showing how the green marketing represents a marketing strategy that influences their purchase decision in Mexican consumers.
\end{abstract}

Keywords: consumer behavior, millennium generation, green marketing

\section{Introduction}

This research explores the evolution on the behavior of the consumer in daily life, and how the society, the culture, the globalization and the media have influenced on their tastes and preferences. It has been recognized that there are consumers that explicitly specify which kinds of products they are attracted to. So consequently it is much easier to hook them if the marketing strategies are efficiently planned when having in mind certain types of targets.

Nowadays purchase decisions are made based on tons of information that is handy and very descriptive, thanks to the information and communication technologies (ICTs). This kind of technology allows the audience to make a quick decision about what to buy, without having seen the product, physically. So thanks to the ICTs, the product, can be described not only in words but it can be visually presented. That is why online shopping has been gaining weight in certain circles like handicapped or elderly people. For these groups of people, online shopping represents the only access they have to buy products. This is why they are considered suitable for the e-commerce (Taken \& Brower, 2012).

An overview of the millennium generation will be released. The information will describe what the tastes and preferences regarding consumption of goods and services of this generation are. What they are attracted to, like brands, and how now these consumers represent a force in the global society as well as the direct influence of the green marketing in them and their purchase decision (Urien, 2011).

Environmental concerns and green marketing are an increasingly important topic for both business and academia. In relation to the latter, Paço \& Reposo (2009) have attempted to identify the characteristics of green consumers and the related marketing implications. It is mostly the case that consumers express a real concern for the environment, but their attitudes are not always translated into their purchasing behaviour.

Although consumers continue to want to satisfy their wants and desires, nowadays, they feel that, at the same time, they should adopt a more active role in the protection, preservation and conservation of the environment. The question is whether they will take into account the environmental aspects when they buy or behave daily. Because at this moment, it is not yet possible to reply to this question with a high degree of certainty, the development of green consumer behaviour models is necessary (Paço, Alves, Shiel, \& Filho, 2013).

This research offers marketers a richer understanding of millennials consumption behavior of green products, in addition to highlighting important cultural behaviors who distinguish Mexican millennials.

\section{Methodology}

The analysis of consumer behavior and its relationship with the green marketing was done through an exploratory descriptive research. Some printed and electronic sources were consulted, as well as specialized 
magazines and journals. This is an exploratory and qualitative research where data collection is aimed to provide a better understanding of the meanings and experiences of Mexican consumers, based on an analytical and contrast induction of the information gathered.

\section{Theoretical Framework}

\subsection{Consumer Behavior}

In recent years the behavior of consumers has been extensively investigated to define how vulnerable they are, many factors have been necessary to be considered. Concepts as culture, subcultures, social classes, and the degree of influence they have on consumer behavior at the time of the purchase have been broadly researched (Durmaz, Celic, \& Oruc, 2011).

Consumers have a complex buying behavior when they are interested in buying a product, and it is possible that they can perceive significant differences between brands. Consumers could be kind of participative when the product is expensive, it involves risks, and it is not always purchased, and expresses many personal issues. The consumer has a lot to learn about the category of product (Hoyer, Maclnnis, \& Pieters, 2014).

Buying behavior that reduces the discomfort occurs when consumers are heavily involved in an expensive purchase, less frequent or risky, but observe a little difference between brands. After purchase, consumers can experience a feeling of discomfort if they perceive disadvantages of the chosen brand or heard favorable comments about brands that they did not choose (Kotler \& Armstrong, 2013).

\subsection{Consumer Behavior Worldwide}

For businesses, understanding the behavior of consumers is not easy within the borders of a country. However, for those operating in many countries understand and address the needs of consumers could become an epic task. Although it is possible that consumers in different countries have some features in common with values, attitudes, and behaviors often vary significantly. Marketers must understand the differences and adjust their products and marketing programs accordingly to the audience.

The typical buying behavior occurs in a low consumer involvement scenario and few significant differences between brands. Sometimes consumers do not look carefully at the names, nor evaluate their characteristics, weight or make decisions regarding which brands to buy. The recurrence of the ads creates brand familiarity instead of belief in the brand.

Consumers do not create attitudes towards a brand; they select it because it is familiar. Since the consumers are not heavily involved in the product purchase, they may not evaluate the process of decision making, and maybe not even after the purchase. Thus, in the purchase process the beliefs about the brand are involved, these beliefs are formed by a passive learning, followed by a purchasing behavior, which may or may not be followed by an evaluation.

Consumers' purchases demonstrate a particular behavioral pattern, seeking for a variety of situations characterized by low participation, but where significant differences between the brands are perceived. In such cases, consumers often make many changes in brands. The marketing strategy may be different for the leading brand in the market that for smaller brands. The market leader will try to keep encouraging the consumer to continue with their habitual buying behavior. The main brand(s) continue leading the shelf spaces at the stores while keeping the shelves stocked and by frequently throwing reminding advertising campaigns.

The purchase motivation is divided into two groups: utilitarian and hedonic. Functional reasons include the traditional approach to marketing research and consumer. As a result, we now know more about them at the expense of hedonic motivations. Utilitarian shopping is more logical rational; it is related to the expenditure, and it is associated with an increase on the information obtained by the purchase. Hedonic behavior is more subjective and depends on the idiosyncrasies of the individuals and its relationship with the perceived value through fun and pleasure (Baruca \& Zolfagharian, 2013).

As a result, the marketing specialist must decide the rate to which their products and marketing programs need to be adapted to meet the unique needs and cultures of consumers in different markets. On the one hand, the specialists should standardize their offerings to simplify operations and take advantage of cost savings. On the other hand, the adaptation of marketing activities for each country will result in products and programs that best meet the needs of local consumers. In recent years, the choice to adapt or standardize the marketing mix in international markets is debatable (Kotler \& Armstrong, 2013).

Consumer behavior is social by nature; this means that consumers should be considered according to it and to their relationships with others. Usually the study of consumer's behavior focuses exclusively on individual 
consumers who buy goods or services for themselves, their families or friends; but there is another type of consumer: formal organizations that buy products and services to use in organizational functions such as production or for resale. Most of the times, the same concepts can be used to understand both behaviors. Both, the individual consumer, and the organizational consumer are affected by the culture where they are immersed in, the leading rules that regulate the buying behavior and the environment that surround them. During the purchasing process, the consumer gathers information about the different alternatives, processes this information, learn about the products and determine which alternative is more suitable for the perceived needs (Fischer \& Espejo, 2011).

\subsection{Environmental Conscious Consumer Behavior}

Consumers are more likely to have an attitude of environmental conservation when they feel they handle the pollution problem, for example. However, if consumers do not often feel responsible for many of the environmental problems they will not feel motivated to be part of the solution. Therefore, for the environmental programs and ecological conservation to succeed, commercial spots must make the problem relevant to the consumers. Also, to educate them on how much money and energy they can save if reducing electricity consumption, for instance. The environmentally conscious behaviors are more likely to occur if consumers perceive that their actions can make a difference, this behavior is known as consumer perceived effectiveness (Hoyer et al., 2014).

\subsection{Consumer}

In recent years research on consumption has been extensively studied. Sociocultural processes and practices, consumer activities, goods, and new brands that support the market myths. These myths are commonly conceptualized as cultural resources that attract consumers to the purchase or the recognition of brands (Zeynep \& Thompson, 2011).

In the business or administration field, when speaking of a consumer, they refer to the person as a consumer. The consumer is the person or organization that the marketing efforts focus on, to guide and to encourage the purchase, by studying the decision-making process of the buyer (Fischer \& Espejo, 2011).

In economics, a consumer is a person or an organization who demands goods or services provided by the producer or supplier of these goods or services. That is to say, it is seen as an agent with a series of needs and desires that has an income that permits to meet those needs and desires through market mechanisms. The legislation that defends consumer is called the consumer rights. It is also defined as the one who consumes or buys products for consumption. It is, therefore, the final actor in various productive transactions.

According to Fischer \& Espejo (2011) consumers and domestic households are the units that make decisions on what to spend and thus, determine the demand for each good or service. However, it is the market demand curve and not the individuals, which along with the offer curve determines the price and, therefore, the amount that is bought and sold.

\subsection{The Millennium Generation}

The defining characteristic of this group is that they reached adulthood at the beginning of the new millennium, that is why the name of "the millennium". According to Rickheim (2011) the millennium generation, also known as "Generation Y", cannot be easily identify by its gender or skin color, because the attitudes, thoughts, perspectives and styles of its member differ from one to another.

The members of this generation are concerned about the environment; they look for "the green" products. They also seek for brands that provide information about the environment, their favorite brands are: Whole Foods, Trader Joe's, Toyota, Honda and Google (Lamb, Hair Jr., \& McDaniel, 2011).

According to some experts, the vast majority of members of the millennium generation consider that the defining attribute of this group is that they entered adulthood around the beginning of the new millennium, therefore the name of "the millennium" (Tobenkin, 2008).

The millennium generation can be seen as the last generation in our postmodern society. They are both individualistic but social, they have traditional family values but are also tolerant and open. They are also more permissive towards sexual and ethical issues than previous generations. They are defined as more positive than Generation X, with a firm conviction of a better future and a better world.

Regarding their brand preferences, they will only be interested in those brands that have a good marketing strategy. Moreover, to those that can arouse their curiosity. If a brand is recognized for being "cool", and innovation develops, this will be the key to increasing loyalty. (Van Den Bergh, J. \& Behrer, M., 2012). 
Those companies and marketing specialists who adjust their brand strategy to meet the needs of this segment will be better connected with them and, therefore, will be more successful. (Reisenwit \& Iyer, 2009).

\subsection{Green Marketing}

It is also known as ecological or green marketing.It is understood as the development and sale of products designed to minimize the negative effects on the environment or to improve it. A company cannot only help the environment through the green marketing, but can help to improve the profits. Some environmental conscious consumers are willing to pay more for green products and make purchasing decisions based primarily on the environmental qualities of the product (Lamb et al., 2011).

Society has realized that its current behavior in the consumption market will bring consequences for the future generations. According to Taken \& Brower (2012), the reports from the most sophisticated means of environmental issues have helped people realize that their personal consumption affects production worldwide.

According to Peattie (2001) the green marketing has been through three phases. The first was named the ecological green marketing. This happened in the sixties and seventies. This phase lists all the activities that seek to solve environmental problems and recognizes the role of the companies, the products, and the consumers to solve the environmental problems that were happening in those decades. The second phase, called environmental green marketing, occurred in the eighties; the purpose was to use clean technology in innovative product design and production systems. The third phase consisted of sustainable green marketing, in the nineties. As Peattie suggested, it is deeper and more meaningful the development of the green marketing, that sees an opportunity for sustainable consumption and production based on the protection and enhancement of natural resources. The consumer is aware of the environmental impact and moreover of those products that create this negative and positive impact.

\section{Proposal Development}

It is important to consider the actions that lead or motivate consumers to complete the purchase process. To professionals from different areas is important to research and analyze every step that motivates consumer behavior to buy or not a product or a service. It represents a tool that requires knowledge of both, the entrepreneur to higher sales, and the consumers, to satisfy their desires or demands, and even the government in the formulation of public policies to understand the behavior of the market and the different economic sectors. This information will lead to the correct decision-making from the perspective of each of those interested in knowing the offer and demand for each product to be more competitive at the international, national and local environment.

Advertisers spend substantial amounts of money on keeping people and groups of people (markets) interested in their products. To succeed, they need to understand what makes potential customers to behave in certain ways. The goal of the advertiser is to obtain enough data about the markets to create accurate buyers profiles, in order to find common spaces for communication. This involves the study of consumer behavior: the mental and emotional processes, and physical activities of people who buy and use goods and services in order to meet individual needs and desires.

Nowadays the green marketing has been used as a marketing strategy, which obviously affects the buying decision for various reasons, among them is fashion, environmental awareness, and the sense of belonging to certain social groups, among others.

Then, we can see the influence on the purchasing behavior on the millennium generation and their interest buying products that do not affect the environment.It has been evident their concern about leaving a cleaner world for the future generations.

Moreover, emotions are also an important variable to consider, as it exerts a significant influence on purchase as well as online shopping. There is a direct positive relationship between the customization of products and purchase intent (Papas, I., Kourouthanassis, P., Giannakos, M., \& Chrissikopoulos, V., 2014). Likewise, online shopping provides many consumers, such as the elderly and disabled, the opportunity to compare and buy products that otherwise would not be possible to do by the traditional means.

The generation called millennials might be the most powerful in consumption, the strongest pillar of this industry in 2017, according to estimates of the software company SAP business. The experience at the time of purchase has become almost as important as the product that will be consumed, according to Lori Mitchell Keller, senior vice president of SAP for Retail industry factor, which characterizes the so call millennials they will represent the 50 percent of global consumption in 2017 (Orozpe, 2014). 
Regarding this, it is important to consider the role that the millennium generation plays in society. Since they represent about 90 million of around 318 million people only in the United States; and approximately two billion people in the world, over 7.1 billion people worldwide. They spend about 200 billion a year, and this figure is expected to double by 2020 (Karr, 2014).

They are a group of young people born between the early eighties to the early 2000 . There are several texts that point to other time ranges; however, these dates were the most accepted following the book Millennials Rising: The Next Great Generation of W. Strauss. This generation has been identified as the responsible for the future of the American nation, and therefore this has added a great deal of attention in the last years (Rattinger, 2014).

The millennium generation observes the reputation of the brands. Read the labels of the products they consume and research about the packaging of products to discerning whether a product is favorable or not to the environment (Taken \& Brower, 2012). According to (Van Den Bergh \& Beher, 2012) millennials are impatient, family oriented, inquisitive, used to give their opinion, diverse, organized, smart street and connected.

People who are concerned to know what companies are doing and how their business operations impact the environment characterize the millennium generation. The psychoanalyst Erick Erickson coined the term generativity in 1950 and is understood as the desire people have to guide future generations (Urien, 2011).

Lu, Bock, \& Joseph, (2013), made a research about Millennial Generation's consumption of green products, a questionnaire was administered to 197 undergraduates at a private university in the southern US. The main findings suggested from this research were that when developing marketing communications, marketers may want to devote more attention to recyclability or re-usability, biodegradableness, and positive health effects stemming from eco-friendly product attributes, as these characteristics shared the strongest associations with Millennial intent to purchase green products.

Ramasamy \& Yeung, (2009) revealed that 61\% of millennials Asian society, those (born between 1979 and 2001) feel that it is their responsibility to make the world a better place to live. While $78 \%$ believe that companies have the responsibility to include them in their efforts.

According to Ataei \& Taherkhani, (2015) Canadian's consumers, in general, prefer environmentally-friendly products with more personal and financial benefits such as fuel-saving products and energy-efficient alternatives over the ones that mainly benefit the environment per se such as biodegradable or recycled products. Consumers under 35 years of age have different levels of willingness to spend more than those who are over 35 . Consumers attribute different rankingsto different features of the product depending on product type and its positioning across the price spectrum: Brand, quality, price and convenience become more important than environmentalfriendliness.

Keeter \& Taylor, (2010) consider that millennium generation transfers all ethical responsibility to organizations, they rarely choose a brand for their altruistic programs. Protecting the planet is not a typical behavior of the millennium generation. It is the result of the spirit of the age, as they recycle as much as other generations and buy organic and friendly environment products the like other generations. For members of the millennium generation is more important not to be bombarded with traditional altruistic programs, but making a difference to have the values and choose how and where their charitable contributions to go (Namiranian, 2006).

Green marketing seems growing as an intellectual sub-discipline of marketing that discusses and examines micro-issues in green marketing more prominently in last 25 years. In early 1990s, literature discussed the relevance of green marketing philosophy in changing orientation of marketing to achieve ecological sustainability objectives. Literature in mid-1990s discussed corporate environmentalism as a market strategy and literature in early 2000s proposed business-level and functionallevel strategies to understand dynamics of marketing green products and to achieve effective firm performance. From mid-2000s onwards, green marketing functions and their marketing consequences registered their strong presence in the literature (Prashant, 2016).

\subsection{Mexicans of the Millennium Generation}

Young millennium in Mexico represent nearly a third of the country's population, as there are over 40 million people who fit into this age group in a country of 119 million inhabitants (Sebreros, 2014).

In many ways, habits and attitudes digital are parallel to those of the most economically advanced markets, but having grown up in a middle-income country, where much of the population has no access to the bank and have been hit by recession history when they began to live, young Mexicans have less financial flexibility than their counterparts in other countries and are less likely to make purchases online.

In Mexican society, the family influence on the pattern of consumption, not only is limited by the father, mother 
and children but also to the extended family; for example the in-laws or the siblings. For Mexicans, it is crucial to have family approval and feel accepted. Deeply concerned about what people say this situation is emphasized in more closed societies like small cities, and is even more obvious in the lower social classes, where it is not rare to find cases where a family lives with their close relatives (Ramos, 2008).

The behaviour patterns in Mexico depend on the economy and employment. So the level of development of the country, with great economic and social differences the price changes on products have to be very dynamic and sensitive to avoid having sharp falls. An example is to offer the products in packages that are more accessible to most of the population. The consumer turns to other brands not because they are disloyal to a brand, but for a necessity; or because the product is not as good as it used to be.

Psychological factors, which comes in first is motivation, since it will generate an impulse to buy. Returning to the motivation theory of Maslow (1954), which prioritizes the needs of an individual and begins from the minor to the most urgent, it is difficult to establish a correlation between the level of consumption of the individual and their needs as they not necessarily follow this order to encourage the purchase of a product or not. The stimuli for the consumer have implications beyond the "needs".

For the analysis of the purchasing behavior of the millennium society, it is important to highlight the exponential growth of population in the last years, which clearly demand more and better goods and services. It would be necessary to do a comparative analysis of the number of people with regular incomes that buy, and with the number of international retail chains that have been established in the city. And the factors that motivate the purchase should also be analyzed.

The influence of migrants who live with a person who is accustomed to living on credit, where the goods are disposable and fashion makes a lifestyle; is causing a cultural shock that is mirrored in the way we buy. Another factor of influence in the current consumer behavior is the impact of mass media; particularly television.

\section{Conclusions}

Nowadays, organizations try to achieve their objectives and goals as fast as possible, buy improving their productive processes in constant innovation. However, as more organizations emerge, the competition becomes more aggressive and entrepreneurs are looking for ways to differentiate and position themselves in the minds of consumers, to grab their attention and finally to reach their preference and loyalty. Therefore the millennium generation, has become a focus group, who are studying in depth, they represent a market in constant growth and whose purchase capacity becomes more evident.

The emotions that particular brands, images, services, awake in the consumers are elements the entrepreneur coins and evaluate in the consumer's perception. These impressions look for subjective aspects of their ads. The idea is to go beyond the rational things and try to see into the unconscious of the consumer, to offer products that apart from being designed individually for them, they awake emotions in the consumer. The satisfaction of getting a goods or service that supports a cause or has been done for a socially responsible company opens the eyes of the millennium generation. This motivates them to purchase that product or also to get away from certain brands that do not respect the environment. Entrepreneurs say that the emotions must be connected to the actions, any speech or action of an external nature that appeals to consumer's emotion either in the form of a product, service, political action, or sports. If excitement is promised, it must include feelings. Otherwise, emotion will maybe touch the consumer but is nor a warrant of loyalty (Casabayó, 2010).

It is important to consider that Mexicans that are part of the millennium generation are strongly influenced by psychosocial factors that are different from any other society, as is the environment in Mexican society which dictates their behavior and orientation towards the green marketing. Furthermore, it would be a second investigation into the environmental performance the members of this subdividing generation as because they belong to groups of age from 15 to 35 years old today and despite having very accurate profiles of their behavior, their mental maturity about the environmental impact varies according to age and other factors .

As stated by Bauman, (2007), the era of identity is full of noise and euphoria. The search for identity divides, separates and encourages builders to look for hooks to hang together the fears and anxieties individually experienced.

\section{References}

Ataei, H., \& Taherkhani, F. (2015). Analysis of Canadian Consumer Spending Patterns toward Green Products. International Journal of Marketing Studies, 7(2). http://dx.doi.org/10.5539/ijms.v7n2p19

Baruca, A., \& Zolfagharian, M. (2013). Cross-border shopping: Mexican Shoppers in the US and American 
Shoppers in Mexico. International Journal of consumer studies, 37(4), 360-366. http://dx.doi.org/10.1111/j.1470-6431.2012.01097.x

Bauman, Z. (2007). La sociedadindividualizada. España: Cátedra.

Casabayo, M. (2010). Fuzzy Marketing. Cómocomprender al consumidorcamaleónico. España: Deusto.

Durmaz, Y., Celik, M., \& Oruc, R. (2011). The Impact of cultural factors on the consumer buying behavior examinated though an empirical study. International Journal of Business and Social Science, 2(5), 109-114.

Fischer, L., Espejo J. (2011). Mercadotecnia. México, D.F.: McGraw Hill.

Hoyer, W., Maclnnis, D., \& Pieters, R. (2014). Comportamiento del consumidor. México, D.F.: Cengage Learning.

Karr, A. (2014). Millennials eager to stop, reclutant to buy. Women's Wear Daily, 207(81), 21.

Keeter, S., \& Taylor, P. (2010). A portrait of generation next confident connected open to change. Retrieved from http://www.pewresearch.org/search/A+portrait + of + generation+next.+confident. + connected. + open+to + chan ge/

Kotler, P., \& Armstrong, G. (2013). Fundamentos de marketing. México, D.F.: Pearson.

Lamb, C. W., Hair Jr., J. F., \&Mc Daniel, C. (2011). Marketing. México, D.F.: Cengage Learning.

Lu, L., Bock D., \& Joseph M. (2013). Green marketing: What the Millennials buy. Journal of Business Strategy, 34(6). http://dx.doi.org /10.1108/JBS-05-2013-0036

Namiranian, L. (2006). Brand engagement teenagers and their brands in emerging markets. Retrieved from http://www.decisionanalyst.com/Downloads/TeenagerWebUse.pdf

Orozpe, N. (2014). Millenialsserán los consumidores del 2017. Retrieved from http://www.merca20.com/millenials-seran-los-consumidores-del-2017/

Paço, A., \& Raposo, M. (2009). Green segmentation: an application to the Portuguese consumer market. Marketing Intelligence \& Planning, 27(3), 364-379. http://dx.doi.org/10.1108/02634500910955245

Paço, A., Alves, H., Shiel, C., \& Filho, W. L. (2013). Development of a green consumer behaviour model. International Journal of Consumer Studies, 37, 414-421. http://dx.doi.org/10.1111/ijcs.12009

Papas, I., Kourouthanassis, P., Giannakos, M., \& Chrissikopoulos, V. (2014). Shiny happy people buying: the role of emotions on personalized e-shopping. Electronic Markets, 24(3), 193-206. http://dx.doi.org/10.1007/s12525-014-0153-y

Peattie, K. (2001). Toward sustainability: the third age of green marketing. The Marketing Review, 2(2), 129-146. http://dx.doi.org/10.1362/1469347012569869

Prashant, K. (2016). State of green marketing research over 25 years (1990-2014). Marketing Intelligence \& Planning, 34(1), 137-158. http://dx.doi.org/10.1108/MIP-03-2015-0061

Ramasamy, B., \& Yeung, M. (2009). Chinese consumer's perception of corporate social responsability. Journal of Business Ethics, 88(1). http://dx.doi.org/10.1007/s10551-008-9825-x

Ramos, S. (2008). El perfil del hombre y la cultura en México. México, D.F.: Colección Austral.

Rattinger, A. (2014). Quienes son los millenials y qué los hace tan importantes? Retrieved from http://www.merca20.com/que-son-los-millenials-y-por-que-hay-que-entenderlos/

Reisenwit, T., \& Iyer, R. (2009). Differences in generation X and generation Y: implications for the organization and marketers. The marketing management journal, 19(2), 91-103.

Rickheim, M. (2011). Capturing the minds and hearts of millennials. Retrieved from http://www.diversityjournal.com/6997-capturing-the-minds-hearts-of-millenials/

Sebreros, M. (2014). Millenials de México, a paso lento en comprasdigitales. Retrieved from http://www.merca20.com/millenials-de-mexico-a-paso-lento-en-compras-digitales/

Taken, K., \& Brower, T. (2012). Longitudinal study of green strategies the influence millennials. Journal of Strategic Marketing. http://dx.doi.org/10.1108/07363761211206339

Tobenkin, D. (2008). Millennials: Youthful and full of expectations. Alaska Business Monthly, 24(3), 20.

Urien, B., \& Kilbourne, W. (2011). Generativity and self-enhancement values in eco-friendly behavioral intentions and environmental responsible consumption behavior. Psychology and Marketing, 28(1), 69-90. 
http://dx.doi.org/10.1002/mar.20381

Van Den Bergh, J., \& Behrer, M. (2012). La generación Y. Quieremásquemarcas cool. México, D.F.: Patria.

Zeynep, A., \& Thompson, C. (2011). Demythologizing Consumption Practices: How consumers protect their field-dependent investment from devaluing marketplace myths. Journal of Consumer Research, 37(5), 791-806. http://dx.doi.org/10.1086/656389

\section{Copyrights}

Copyright for this article is retained by the author, with first publication rights granted to the journal.

This is an open-access article distributed under the terms and conditions of the Creative Commons Attribution license (http://creativecommons.org/licenses/by/3.0/) 